\title{
Prostate cancer presenting as perianal swelling: Case report
}

\author{
Ahmed A Abou-Zeid, ${ }^{a}$ MD FRCS(Ed); Hany Hamed, ${ }^{b} M D$ \\ a) Department of General Surgery, Ain-Shams University, Cairo, Egypt \\ b) Department of Urology, Ain-Shams University, Cairo, Egypt
}

\begin{abstract}
We are reporting a case of locally advanced cancer prostate that presented by a huge perianal swelling. We are unaware of a similar presentation that has been previously reported in literature.
\end{abstract}

\section{Introduction:}

Prostate cancer is a common malignancy in males. It rarely occurs before the age of 50 years and the incidence increases through the ninth decade of life. ${ }^{1}$ Ninety percent of the new cases of prostate cancer are expected to be diagnosed at local or regional stages, for which 5-year relative survival approaches $100 \% .^{2}$ Advanced T stage is characterized by extension of the tumor outside the prostatic capsule to invade nearby structures such as the bladder, the seminal vesicles, the ureters and the pelvic side walls. ${ }^{1}$ Further local extension is rare. We are reporting a patient with locally advanced prostatic carcinoma who presented for the first time by a perianal swelling. We believe this is the first case to be reported in literature.

\section{Case report:}

A male patient, 62 years old presented to the Outpatient Department complaining of a huge swelling near the anal verge of 7 months duration. The swelling was painless and it gradually increased in size since it first appeared. The patient did not recall any possible etiology for that swelling. The patient had no history of trauma to the anal region nor fever and he had no symptoms suggestive of urinary outflow obstruction. Similarly, there were no symptoms suggestive of any rectoanal pathology and the patient did not notice other swellings in the body. The patient did not have any bleeding tendency and he was not on anticoagulants. There was neither loss of weight nor loss of appetite. History of other systems disorders, past history and family history were insignificant. The patient was a known diabetic for 20 years and he was on oral hypoglycemics.
General and abdominal examinations were insignificant.

Inspection of the anal region revealed a huge swelling situated to the left of the anal verge and extending anteriorly to the perineum and scrotum and posteriorly to the anococcygeal region (Fig. 1). The swelling was distorting the anal orifice and the overlying skin was normal. The swelling was neither hot nor tender. It was frankly cystic, however, on deep palpation, a solid tumor could be felt amidst the perianal fluid. The inguinal lymph nodes were not palpable. Digital rectal examination was significant for moderate smooth enlargement of the left lobe of the prostate that was not harboring suspicious nodules.

Except for moderate anemia ( $\mathrm{Hb} 11 \mathrm{gm} / \mathrm{dl})$, all routine blood tests were essentially normal. The PSA was markedly elevated $(1788 \mathrm{ng} / \mathrm{ml})$, other tumor markers (CEA and CA 19.9) were normal. Endorectal ultrasound showed marked enlargement of the left lobe of the prostate that was smooth and homogenous. The swelling was abutting, but not distorting, the left side of the anorectum (Fig. 2). Pelviabdominal MRI revealed a big tumor of the left lobe of the prostate that extended downwards along the antrolateral wall of the rectum, then through the pelvic floor to the left side of the anal canal until it reached the left perianal region (Fig. 3 ). There was no further extension to pelvic sidewalls or pelvic organs and there was no pelvic or abdominal lymphadenopathy. IVU showed smooth basal elevation of the urinary bladder slightly more evident on the left side. There was no evidence of backpressure on the kidneys or ureters. Chest $\mathrm{X}$ ray was free.

Further diagnostic workup included 


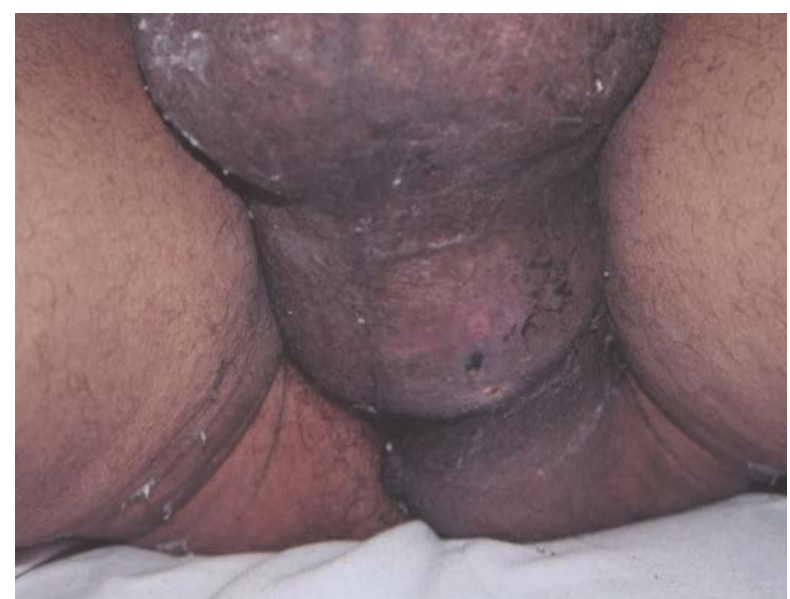

(Fig. 1)

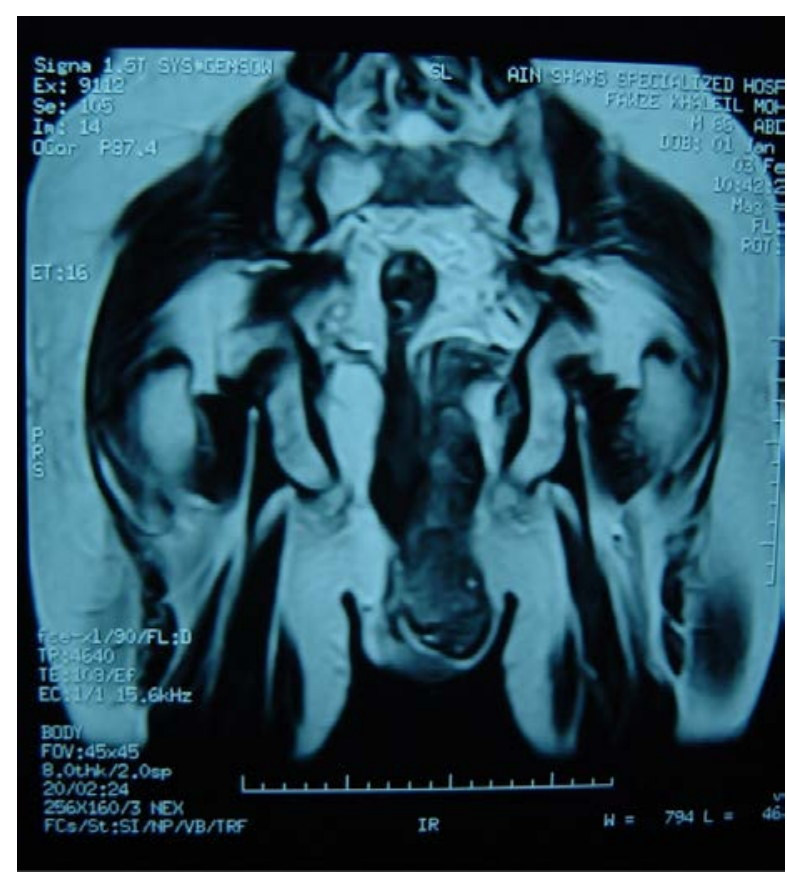

(Fig. 3)

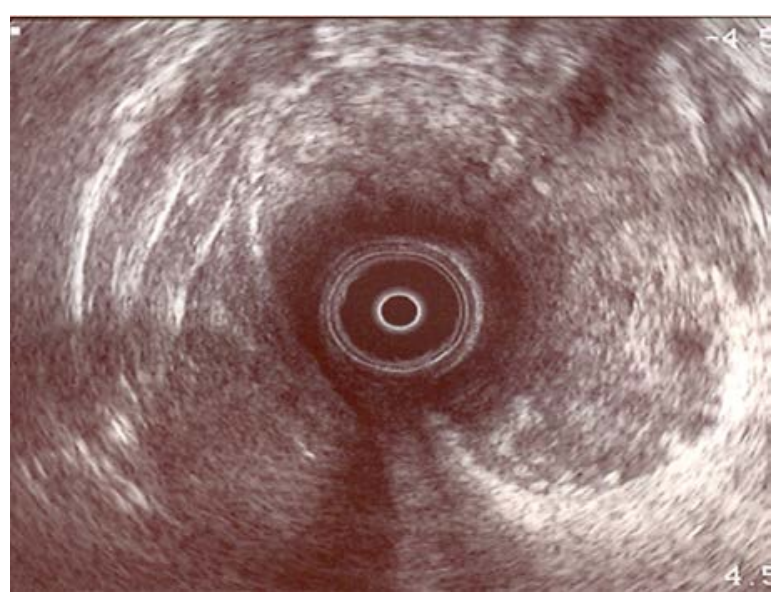

(Fig. 2)

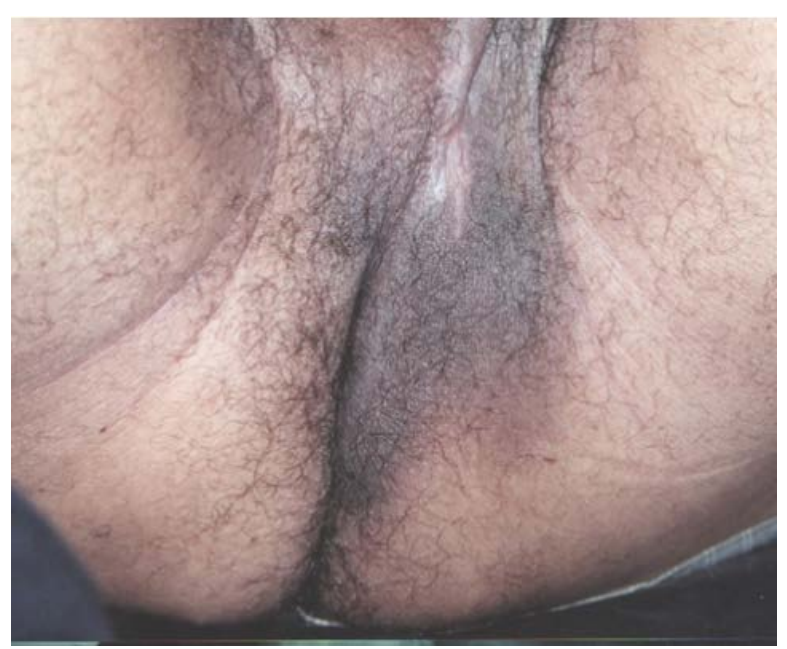

(Fig. 4) 
aspiration of the perianal fluid and tru-cut biopsy of the solid perianal swelling. The aspirate was serosanguinous and it was negative for malignant cells. The biopsy result was significant for well-differentiated adenocarcinoma of the prostate. Metastatic workup revealed the presence of skeletal metastases at mid posterior part of the right sixth rib and left femoral head and T4 N0 M1 prostatic carcinoma was diagnosed. The patient was offered to have bilateral orchidectomy but he refused. He was put on Zoladex ${ }^{\circledR} 3.6 \mathrm{mg}$ (AstraZeneca, Macclesfield Cheshire, United Kingdom) once monthly subcutaneous injection to which the patient showed marvelous response. The swelling gradually decreased in size until it completely disappeared after 5 months (Fig. 4) and the PSA level dropped to normal. Until the time of writing this report, thirteen months after starting hormonal treatment, the patient is asymptomatic and his PSA levels are within the normal limits.

\section{Discussion:}

Cancer prostate is one of the leading causes of cancer deaths in men in the United States. ${ }^{2}$ It is estimated that 30-50 percent of men older than 50 years have histologic evidence of prostate cancer at autopsy, while at age 75 or older, it is estimated that this figure increases to $50-70$ percent. ${ }^{3}$ Early stage of the disease is typically asymptomatic. Those patients are discovered during either routine digital rectal examination or routine estimation of prostatespecific antigen. Some of those patients are also discovered in biopsy specimens of transuretheral resection for benign prostatic disease. As the tumor advances, symptoms gradually appear in the form of local urinary symptoms such as hesitancy, frequency and urgency, or systemic symptoms as general ill health, weight loss, fatigue and bone pain, signifying distant metastases. ${ }^{3}$

Extraglandular carcinoma occurs when the disease is locally advanced to invade nearby structures such as the bladder, the seminal vesicles, the ureters and the levator ani and pelvic sidewalls. Although the rectum is in direct posterior relation to the prostate, its invasion by prostatic carcinoma is rare because it is protected by the Denonvillier's fascia. ${ }^{1}$ Distant metastases from prostate cancer can also occur to pelvic and distant nodes, lung, bone and liver. Rare sites that have been reported to harbor metastases from prostatic carcinoma include the kidney, ${ }^{4}$ testes, 5 adrenals, ${ }^{6}$ orbit, ${ }^{7}$ breast, ${ }^{8}$ umbilicus, ${ }^{9}$ skeletal muscle, ${ }^{10}$ and central nervous system. ${ }^{11,12}$ Although perineal seeding has been reported to occur along the needle track after transperineal biopsy from prostatic carcinoma, 13,14 and after minimally invasive treatment of prostatic carcinoma by brachytherapy ${ }^{15}$ and cryosurgery, ${ }^{16}$ we are unaware of any previous report of locally advanced cancer prostate presenting by a perianal swelling. Other rare presentations of primary or metastatic prostate cancer include visual changes, ${ }^{7}$ Cushing's syndrome, ${ }^{17}$ lumbosacral radiculopathy, ${ }^{18}$ hypoglossal nerve palsy, ${ }^{19}$ superior vena cava obstruction, ${ }^{20}$ and generalized lymphadenopathy. ${ }^{21}$

In the present case report, although the tumor was very advanced locally, yet it did not give any urologic or rectal symptoms. Moreover, digital rectal examination, although significant for enlarged left lobe of the prostate gland, it was not suspicious for prostatic carcinoma. This can be explained by the fact that the tumor originated in the peripheral prostatic zone, the most common site of origin of prostatic carcinoma, ${ }^{3}$ and that it exhausted itself in extending in the periprostatic tissues between the distal gastrointestinal and urinary tracts. Thus, rather than obstructing or distorting either of them to give urinary or rectal symptoms, it remained asymptomatic until it appeared in the perianal region when it warned the patient for its presence. The IVU, ultrasound and MRI pictures, by not showing evidence of backpressure or lumen distortion, emphasize this explanation.

In the present report, it was not unexpected to detect distant metastases because the primary tumor was very extensive. Despite its extensive nature, being a hormone dependant tumor, marvelous response to hormone therapy has been noticed. This is maintained at 13 months. Although non-curative, this treatment will be giving the patient at least good palliation and quality of life for some time.

\section{References:}

1- Drago JR, Badalament RA: Prostatic 
carcinoma: an overview. In: Crawford ED, Das S, Current genitourinary cancer surgery. Philadelphia, London, Lea \& Febiger, 1990: 148-61.

2- Jemal A, Murray T, Ward E, et al: Cancer statistics, 2005. CA Cancer J Clin 2005; 55:10-30.

3- Huang SF, Dinney CP: Genitourinary cancer. In: Feig BW, Berger DH, Fuhrman GM, The MD Anderson surgical oncology handbook. Philadelphia, USA, Lippincott Williams \& Wilkins, 2004: 425-44.

4- Denti F, Wisard M, Guillou L, Francke ML, Leisinger HJ: Renal metastasis from prostatic adenocarcinoma: a potential diagnostic pitfall. Urol Int 1999; 62:1713.

5- Manikandan R, Nathaniel C, Reeve N: Bilateral testicular metastases from prostatic carcinoma. Int J Urol 2006; 13:476-7.

6- Long MA, Husband JE: Features of unusual metastases from prostate cancer. B. r J Radiol 1999; 72:933-41.

7- Lavasani L, Zapanta PE, Tanna N, Sadeghi $\mathrm{N}$ : Metastasis of prostatic adenocarcinoma to sphenoid sinus. Ann Otol Rhinol Laryngol 2006; 690-3.

8- Cheng CW, Chan LW, Ng CF, Chan CK, Tse MK, Lai MM: Breast metastasis from prostate cancer and interpretation of immunoreactivity to prostate-specific antigen. Int J Urol 2006; 13:463-5.

9- Fukuda H, Saito R: A case of Sister Mary Joseph's nodule from prostatic cancer. $J$ Dermatol 2006; 33:46-51.

10- Ward AJ, Bourke JB: Skeletal muscle metastasis from prostatic carcinoma. $J$ Urol 1984; 131:769.

11- Lath CO, Khanna PC, Gadewar S, Patkar DP: Intracranial metastasis from prostatic adenocarcinoma simulating meningioma. Australas Radiol 2005; 49:497-500.

12- Lyons MK, Drazkowski JF, Wong WW, Fitch TR, Nelson KD: Metastatic prostate carcinoma mimicking meningioma: case report and review of the literature. Neurologist 2006; 12:48-52.

13- Baech J, Gote H, Raahave D: Perineal seeding of prostatic carcinoma after trucut biopsy. Urol Int 1990; 45:370-1.

14- Szentgyorgyi E: Perineal prostatic cancer seeding following Urocut needle biopsy. Int Urol Nephrol 1996; 28:87-90.

15- Teh BS, Chou CC, Schwartz MR, Mai W, Carpenter LS, Butler EB: Perineal prostatic cancer seeding following radioactive seed brachytherapy. J Urol 2001; 166:212.

16- Downey DB, Chin JL, Williams JC: Perineal prostate cancer seeding along needle tract following cryosurgery. Can J Urol 1999; 6:823-5.

17- Haukaas SA, Halvorsen OJ, Nygaard SJ, Paus E: Cushing's syndrome in prostate cancer. An aggressive course of prostatic malignancy. Urol Int 1999; 63:126-9.

18- Ladha SS, Spinner RJ, Suarez GA, Amrami KK, Dyck PJ: Neoplastic lumbosacral radiculoplexopathy in prostate cancer by direct perineural spread: an unusual entity. Muscle Nerve 2006; 34:659-65.

19- Shah SH: Reversible isolated unilateral hypoglossal nerve palsy due to metastatic prostate cancer. Palliat Med 2006; 20:63940.

20- McGarry RC: Superior vena cava obstruction due to prostate carcinoma. Urology 2000; 55:436.

21- Moura FM, Garcia LT, Castro LP, Ferrari TC: Prostate adenocarcinoma manifesting as generalized lymphadenopathy. Urol Oncol 2006; 24:216-9. 